\title{
Characterization of a novel laccase purified from the fungus Hohenbuehelia serotina and its decolourisation of dyes
}

\author{
Yingyin Xu' ${ }^{1}$ Yuxiao Lu², Rui Zhang ${ }^{1}$, Hexiang Wang ${ }^{1}$ and Qinghong Liu ${ }^{1 凶}$ \\ 1State Key Laboratory for Agro-biotechnology, Department of Microbiology and Immunology, China Agricultural University. Beijing, People's \\ Republic of China, ${ }^{2}$ Department of Envioronmental and Chemical Engenineering, Tangshan College, People's Republic of China
}

\begin{abstract}
A novel laccase was purified from the white rot fungus, Hohenbuehelia serotina, to investigate the applications of this laccase in the decoloration of various dyes. SDS-PAGE revealed a single band of this laccase corresponding to a molecular weight of approximately $57.8 \mathrm{kDa}$. The enzyme showed activity towards several substrates, the most sensitive of which was 2,2'-Azinobis-(3-ethylbenzthiazoline-6-sulphonate) (ABTS). The highest enzymatic activity using $A B T S$ as a substrate was observed at $\mathrm{pH} 6.8$ and $30^{\circ} \mathrm{C}$. The enzyme activity was found to be significantly enhanced in the presence of $\mathrm{Zn}^{2+}$ ions and inhibited by $\mathrm{Fe}^{2+}$ ions. Moreover, SDS and $\beta$-mercaptoethanol were inhibitory, and inhibition by L-cysteine was observed while EDTA and DMSO had almost no inhibitory effect. The laccase could effectively decolorize seven different dyes within 30 minutes at $40^{\circ} \mathrm{C}$.
\end{abstract}

Key words: Hohenbuehelia serotina, laccase. purification, decolouration

Received: 25 June, 2015; revised: 22 September, 2015; accepted: 23 September, 2015; available on-line: 24 October, 2015

\section{INTRODUCTION}

Laccase (EC 1.10.3.2), an oxidase belonging to the blue multi-copper oxidase family, is widely distributed in bacteria (Khandare et al., 2012), fungi (Wu et al., 2010; Freixo et al., 2012) and some plants (Gutierrez et al., 2012). Among these, white-rot fungi have received special attention due to their capability of lignin biodegradation through secretion of oxidative enzymes such as peroxidase (Saranyu, 2009) and laccases (Halaburgi et al., 2011). However, most of these identified laccases have low enzymatic activity and mesophilic stability (Baldrian, 2006; Hilden et al., 2009). Owing to their diversity, laccases are capable of oxidizing a broad range of substrates including phenols, diamines, and various non-phenolic compounds (Champagne \& Ramsay, 2007; Asgher et al., 2008; Jia et al., 2012). Among these, complex azo and anthraquinone dyes are the most discussed (Enayatzamir et al., 2009; Meng et al., 2012).

The sewage produced by textile industries is often strongly colored due to the presence of dye waste. The dyes that are currently used cannot be degraded or removed with physical and chemical processes; besides, the degraded products are more toxic than the dyes (Mohorcic et al., 2006; Khlifi et al., 2010; Verma et al., 2010). These toxins cannot only be leached into the environment through contaminated water and adversely impact all organisms but they can also be inhaled and absorbed directly. Laccases are used in paper bleaching (Kahraman
\& Yesilada, 2001), bioremediation (Cea et al., 2010), and dye decoloration (Robinson \& Nigam, 2008; Zhao et al., 2012). Since laccases eliminate a wide range of pollutants from waste water, the ability of laccase producing microorganisms and novel laccases is of immense interest to environmental biotechnologists. Consequently, discovery of novel laccases with higher enzymatic activity and enhanced stability is highly desirable. We describe the purification and characterization of a novel laccase from the white-rot fungus, Hohenbuehelia serotina in the present study. We also investigated the effects of $\mathrm{pH}$, temperature, metal ions and putative inhibitors on the laccase. Furthermore, we investigated the applications of this laccase in the decoloration of various dyes and the optimun of decolouring conditions involved.

\section{MATERIALS AND METHODS}

Materials. ABTS, N,N-dimethyl-1,4-phenylenediamine, Pyrogallol, 2-methylcatechol, and tyrosine, DEAE-Cellulose and CM-Cellulose were bought from Sigma-Aldrich (St. Louis, MO, USA). Molecular mass standards were obtained from GE Healthcare, USA. All other chemicals were of analytical grade.

Dyes used in the experiment were bought from Zhenyang dye chemical industry Co. Ltd. (Yixing, Jiangsu, China).

Purification of $\boldsymbol{H}$. serotina laccase. Purification of laccase from the fungus was conducted as described by Kim et al. (Kim \& Shoda, 1999). Dried fruit bodies $(50 \mathrm{~g})$ were homogenized in saline. The homogenate was centrifuged at $18000 \times g$ for $15 \mathrm{~min}$ at $4^{\circ} \mathrm{C}$. The supernatant was dialyzed with $10 \mathrm{mM}$ Tris-HCl buffer $(\mathrm{pH}$ 7.5). It was then passed through a $2.5 \mathrm{~cm} \times 30 \mathrm{~cm} \mathrm{DE}$ AE-Cellulose column. After removal of the unabsorbed fraction D1, adsorbed proteins were desorbed stepwise with $150 \mathrm{mM} \mathrm{NaCl}, 300 \mathrm{mM} \mathrm{NaCl}$ and $1 \mathrm{M} \mathrm{NaCl}$ in Tris- $\mathrm{HCl}$ buffer to yield fractions D2, D3 and D4. Fraction D2 with laccase activity was then subjected to ion exchange chromatography on a $2.5 \mathrm{~cm} \times 20 \mathrm{~cm}$ column of CM-cellulose in $10 \mathrm{mM} \mathrm{CH}_{3} \mathrm{COONa}-\mathrm{CH}_{3} \mathrm{COOH}$ (NaAc-HAc) buffer ( $\mathrm{pH}$ 5.4). The unadsorbed fraction

\footnotetext{
e-mail: qhliu@cau.edu.cn
}

Abbreviations: ABTS, 2,2'-Azinobis- (3-ethylbenzthiazoline-6-sulphonate); CBB, Coomassie Brilliant Blue; R-3G, Reactive scarlet: $\mathrm{R}-4 \mathrm{GLN}$, reactive brilliant yellow; R-RV, reactive brilliant blue; $R E S$, reactive emerald blue; RW, active super navy blue; RBBR, Remazol Brilliant Blue; M-GR, malachite green; $A-O R$, active orange ; $\mathrm{X}-3 \mathrm{~B}$, active red; K-BR, active black; CM, carboxymethyl; DEAE, diethylaminoethyl; FPLC, Fast Protein Liquid Chromatography; HPLC, High Performance Liquid Chromatography; Tris, N-tris (hydroxymethy) aminomethane; $\beta-M E$, $\beta$-mercaptoethanol 
C1 was removed with the same buffer. Thereafter, the adsorbed proteins were eluted sequentially with $150 \mathrm{mM}$ $\mathrm{NaCl}$ and $1 \mathrm{M} \mathrm{NaCl}$ in $10 \mathrm{mM} \mathrm{NaAc}-\mathrm{HAc}$ buffer (pH 5.4) to yield fractions $\mathrm{C} 2$ and $\mathrm{C} 3$. Fraction $\mathrm{C} 2$ after ultrafiltration was further purified by gel filtration on a fast protein liquid chromatography (FPLC) Superdex 75 column (GE Healthcare) in $0.2 \mathrm{M} \mathrm{NH}_{4} \mathrm{HCO}_{3}$ buffer ( $\mathrm{pH}$ 8.5). The first peak constituted purified laccase.

Molecular mass determination of the isolated laccase. Sodium dodecyl sulfate polyacrylamide gel electrophoresis (SDS-PAGE) was carried out following the procedure of Laemmli and Favre (1973), using a 12\% resolving gel and a 5\% stacking gel. The gel was stained with Coomassie Brilliant Blue (CBB). FPLC-gel filtration was conducted in a Superdex 75 column that had been calibrated with molecular mass standards.

Assay for laccase activity. Laccase activity was determined by the method involving oxidation of ABTS. The ABTS is oxidized by laccase to the more stable and preferred state of the cation radical. The concentration of the cation radical responsible for the intense blue-green color can be correlated to enzyme activity and is read at $420 \mathrm{~nm}$ (Kim \& Shoda, 1999). Oxidation of ABTS was monitored by determining the increase in $\mathrm{A}_{420}$. In brief, $10 \mu \mathrm{L}$ laccase solution was incubated with $190 \mu \mathrm{L} 1 \mathrm{mM}$ ABTS (in $50 \mathrm{mM}$ sodium acetate buffer, $\mathrm{pH}$ 5.2) at $30^{\circ} \mathrm{C}$ for $5 \mathrm{~min}$. Subsequently, the reaction was ended by adding $200 \mu \mathrm{L} \mathrm{10 \%} \mathrm{(w/v)} \mathrm{trichloroacetic} \mathrm{acid.} \mathrm{Absorb-}$ ance was read at $420 \mathrm{~nm}$ in a spectrophotometer against a suitable blank. One unit was defined as the amount of laccase that oxidized $1 \mu \mathrm{mol}$ of ABTS substrate per min. All determinations were performed in triplicate.

Determination of physicochemical properties of the isolated laccase. The optimal $\mathrm{pH}$ value of the purified laccase was determined in buffers with different $\mathrm{pH}$ values (from $\mathrm{pH} 2.0$ to $\mathrm{pH} 9.8$ ) at $30^{\circ} \mathrm{C}$. The optimal temperature was tested by determining the activity of the enzyme at different temperatures ranging from 20 to $90^{\circ} \mathrm{C}$ in sodium acetate buffer $(\mathrm{pH} \mathrm{6.8)}$. The effects of metal ions $\left(\mathrm{K}^{+}, \mathrm{Mg}^{2+}, \mathrm{Ca}^{2+}, \mathrm{Zn}^{2+}, \mathrm{Mn}^{2+}, \mathrm{Fe}^{3+}\right.$, and $\mathrm{Al}^{3+}$ ) and inhibitors ( $\beta$-mercaptoethanol, EDTA, LCysteine, DMSO and SDS) on laccase activity were also investigated after incubation in sodium acetate buffer (pH 6.8) for $60 \mathrm{~min}$ at $30^{\circ} \mathrm{C}$.

Assay of substrate specificity of isolated laccase. Activity toward several aromatic substrates was tested to determine enzyme specificity. The following substrates were added to a final concentration of $10.0 \mathrm{mM}$ : ABTS, N,N-dimethyl-1,4-phenylenediamine, 2-methylcatechol, Pyrogallol and tyrosine. The enzyme assay was performed as described above in $50 \mathrm{mM}$ sodium acetate buffer, $\mathrm{pH}$ 6.8. The rate of substrate oxidation was determined by monitoring the change in absorbance of the substrate using the published molar extinction coefficient $(\varepsilon)$.

Decolorization of dyes by the purified laccase. Reactive scarlet (R-3G, $\lambda_{\max } 510 \mathrm{~nm}$ ), reactive brilliant yellow (R-4GLN, $\lambda_{\max } 430 \mathrm{~nm}$ ), reactive brilliant blue (R$\mathrm{RV}, \lambda_{\text {max }} 590 \mathrm{~nm}$ ), reactive emerald blue (RES, $\lambda_{\text {max }} 630$ $\mathrm{nm}$ ), active super navy blue (RW, $\lambda_{\max } 595 \mathrm{~nm}$ ), Remazol Brilliant Blue (RBBR, $\lambda_{\max } 590 \mathrm{~nm}$ ), malachite green (M-GR, $\lambda_{\max } 610 \mathrm{~nm}$ ), active orange (A-OR, $\lambda_{\max } 475$ $\mathrm{nm})$, active red (X-3B, $\left.\lambda_{\max } 517 \mathrm{~nm}\right)$, active black (K$\mathrm{BR}, \lambda_{\max } 597 \mathrm{~nm}$ ) and coomassie brilliant blue (CBB, $\lambda_{\max } 580 \mathrm{~nm}$ ) were used in this study. All maximum absorption wavelengths were detected with full wavelength scanning using a UV spectrophotometer.

The decolorization reaction was carried out at $30^{\circ} \mathrm{C}$ for $5 \mathrm{~h}$ in a $6 \mathrm{ml}$ reaction system containing $0.3 \mathrm{mg}$ dye prepared in $25 \mathrm{mM}$ sodium acetate buffer at $\mathrm{pH} 6.8$ and $1.5 \mathrm{U}$ purified laccase. Control containing heat-denatured enzyme was used to measure decolorization of dye. Choose dyes that have higher decolorizing efficiency to analyze optimal decoloring conditions. The optimal decoloring time was determined by spectrum detecting under $2 \mathrm{~h}, 4 \mathrm{~h}$ and $6 \mathrm{~h}$, respectively. Also, the degradation rate was detected by changes of values at maximum absorption wavelengths.

Decolorization was determined as below:

$$
\text { Decolorization }(\%)=100 \times \frac{\text { absorbance }_{t 0}-\text { absorbance }_{t f}}{\text { absorbance }_{t 0}}
$$

Where absorbance $_{t 0}$ is the absorbance value at $\lambda_{\max }$ of each reaction mixture before incubation with enzyme and absorbance ${ }_{t f}$ is the absorbance value at $\lambda_{\max }$ after incubation with the enzyme.

It is not accurate enough to judge dyes decolorizing effect only depending on changes in absorbance value. In order to further confirm whether dyes have been degraded, we use the high performance liquid chromatography (HPLC) (Aglient 1100 series, Eclipse Hypersil ODS $\left.\mathrm{C}^{18}, 5 \mu \mathrm{M}, 4.6 \times 150 \mathrm{~mm}\right)$ to analyze M- GR processed by laccase. The basic parameters were as follows:

Flowing phase: acetonitrile $-5 \mathrm{mM}$ pH4.5 Ammonium acetate buffer (volume 70:30); Flow rate: $0.5 \mathrm{~mL} /$ min; Column temperature: room temperature; detection wavelength: $600 \mathrm{~nm}$; Sample volume: $20 \mu \mathrm{L}$.

\section{RESULTS}

\section{Purification of $H$. serotina laccase}

The H. serotina extract was resolved on DEAE-cellulose into four fractions D1, D2, D3 and D4, using $\mathrm{NaCl}$ at different concentrations (Fig. 1a). Only the adsorbed fraction D2 was found to possess laccase activity. Fraction D2 was further fractionated on CM-cellulose into three fractions C1, C2 and C3 (Fig. 1b). Fraction C2, which contained the bulk of laccase activity, was separated into two major fractions S1 and S2 on Superdex 75 column after ultrafiltration. Laccase activity was found in fraction S1 (Fig. 1c). Based on the elution volume, the molecular mass of S1 was deduced to be about 57.8 $\mathrm{kDa}$. In addition, fraction $\mathrm{S} 1$ displayed a single band with a molecular mass of approximate $57 \mathrm{kDa}$ in SDS-PAGE (Fig. 1d). The yields and specific laccase activities at various stages of purification are shown in Table 1.

\section{Effects of $\mathrm{pH}$ and temperature on laccase activity}

The temperature profile of the purified laccase with ABTS as substrate is shown in Fig. 2. The laccase activity demonstrated a smooth and stable increase as the temperature was increased from $4^{\circ} \mathrm{C}$ to $30^{\circ} \mathrm{C}$, and the activity was found to be maximal at $30^{\circ} \mathrm{C}$. The laccase activity decreased drastically when the temperature was over $70^{\circ} \mathrm{C}$. The thermal stability of the purified laccase was determined upon pre-incubation within a temperature range of $30-60^{\circ} \mathrm{C}$ for $3 \mathrm{~h}$ (Fig. 2). At temperatures below $40^{\circ} \mathrm{C}$, there was almost no change in enzymatic activity. It was only at temperatures over $50^{\circ} \mathrm{C}$ that the remaining laccase activity dropped to below $70 \%$ of the initial activity. These results indicated that the laccase showed better thermo-stability properties than several other fungal laccases (Hilden et al., 2009; Shraddha et al., 2011). 

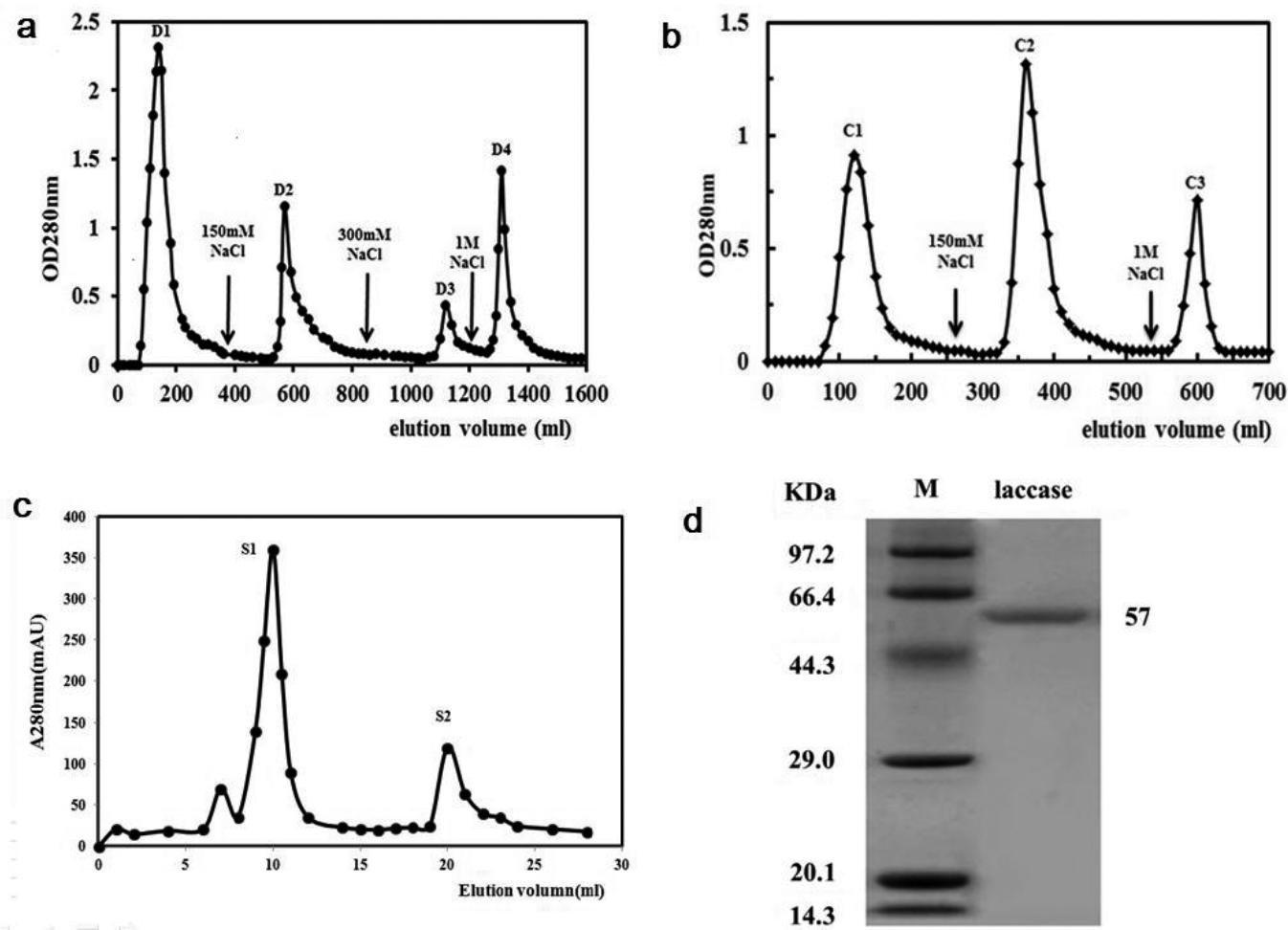

Figure 1. Elution profiles of laccase from $H$. serotina.

(a) Anion exchange chromatography of crude extract of $H$. serotina on a DEAE-cellulose column $(2.5 \mathrm{~cm} \times 30 \mathrm{~cm}$, Sigma). Starting buffer: $10 \mathrm{mM}$ Tris-HCl buffer (pH 7.5). Fractions D2, D3, and D4 were acquired by sequential elution with $150 \mathrm{mM} \mathrm{NaCl}, 300 \mathrm{mM} \mathrm{NaCl}$, and $1 \mathrm{M} \mathrm{NaCl}$ in Tris- $\mathrm{HCl}$ buffer, respectively. Laccase activity resided in fraction D2. (b) Cation exchange chromatography of fraction D2 on a CM-cellulose column $(2.5 \mathrm{~cm} \times 20 \mathrm{~cm})$. Starting buffer: $10 \mathrm{mM} \mathrm{NaAc-HAC}$ buffer $(\mathrm{pH}$ 5.4). Arrows indicate successive elution with $150 \mathrm{mM} \mathrm{NaCl}$ in NaAc-HAC buffer and $1 \mathrm{M} \mathrm{NaCl}$ in NaAc-HAC buffer, respectively. Laccase activity was enriched in fraction C2. (c) Gel filtration by fast protein liquid chromatography on a Superdex 75 column. The molecular mass of S1 was estimated to be $60 \mathrm{kDa}$. Buffer: $0.2 \mathrm{M} \mathrm{NH}_{4} \mathrm{HCO}_{3}$ (pH 9.2). Flow rate: $0.5 \mathrm{ml} / \mathrm{min}$. Fraction size: $0.8 \mathrm{ml}$. (d) SDS-PAGE of purified $H$. serotina laccase. $\mathrm{M}$ is the protein marker. Molecular mass of $\mathrm{H}$. serotina laccase was estimated to be about $57 \mathrm{kDa}$. M: marker; Purified laccase is shown in the other lane.

The optimum $\mathrm{pH}$ value of the purified laccase for ABTS oxidation was found to be $\mathrm{pH} 6.8$ (Fig. 3). The laccase activity declined continuously at every $\mathrm{pH}$ value and we got relative stability value at 6.8 (Fig. 3). These results revealed that $H$. serotina laccase had stability within a wide range of $\mathrm{pH}$ values, which is different from many of the previously described fungal laccases (Giardina et al., 2010; Villalba et al., 2010).

\section{Effects of metal ions and inhibitors on isolated laccase}

The laccase activity was not significantly affected in the presence of $\mathrm{K}^{+}$. The enzyme was strongly inhibited by $\mathrm{Fe}^{2+}$ ions while $\mathrm{Zn}^{2+}$ ions increased the laccase activity at concentrations under $50 \mathrm{mM} . \mathrm{Mg}^{2+}, \mathrm{Mn}^{2+}, \mathrm{Ca}^{2+}$ and $\mathrm{Al}^{3+}$ ions brought about varying degrees of suppression (Table 2). We also tested the sensitivity of the laccase to several putative laccase inhibitors (Table 3). Laccase was inhibited by sodium dodecyl sulfate and $\beta$-mercaptoethanol, suggesting that disulfide bonds are essential for enzyme activity. EDTA and DMSO up to a concentration of $50 \mathrm{mM}$ could not inhibit laccase activity, while a $10 \%$ inhibition was observed with L-cysteine at $25 \mathrm{mM}$.

\section{Assay of substrate specificity of isolated laccase}

We also analyzed the activity of $H$. serotina laccase toward various substrates, including polyphenolic substrates (pyrogallol), methoxy-substituted phenols (2-methylcatechol), aromatic diamines (N,N-dimethyl-1,4-phenylenediamine), and the non-phenolic heterocyclic compound ABTS to determine substrate specificity (Table 4). The highest activity was found with ABTS which was then

Table 1. Summary of purification of $H$. serotina laccase with ABTS as substrate (from $10 \mathrm{~g}$ dry fruiting bodies)

\begin{tabular}{|c|c|c|c|c|c|}
\hline Fraction & Total protein (mg) & Total activity (units) & Specific activity (units/mg) & Yield (\%) & Purification fold \\
\hline Crude extract & 2699.2 & 3696 & 1.37 & 100 & 1 \\
\hline precipitate & 404.2 & 1792 & 4.44 & 48.48 & 3.24 \\
\hline D2 & 152.1 & 1177.2 & 7.74 & 31.85 & 5.65 \\
\hline $\mathrm{C} 2$ & 16.9 & 928 & 54.91 & 25.11 & 40.08 \\
\hline S2 & 3 & 247.9 & 82.7 & 6.7 & 60.36 \\
\hline
\end{tabular}

Data are mean values from triplicate experiments. 

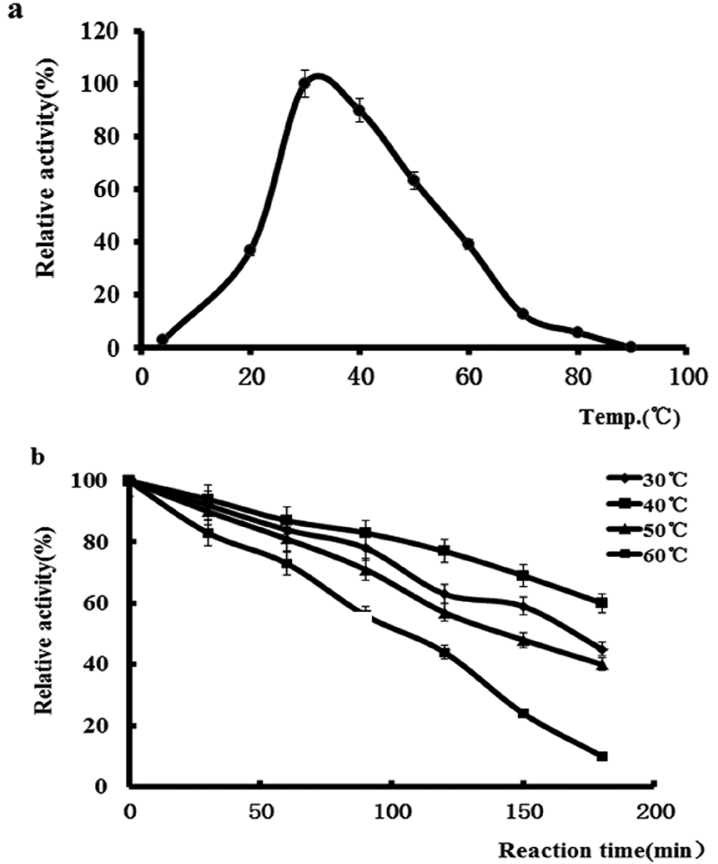

Figure 2. Optimum reaction temperature and thermostability of H. serotina laccase.

(a)The effect of different temperatures on the activity of $\mathrm{H}$. serotina laccase in oxidation of ABTS substrate. (b) Relative activity was tested after pre-incubation of laccase at different temperatures ( $3 \mathrm{~h}$ at each temperature).
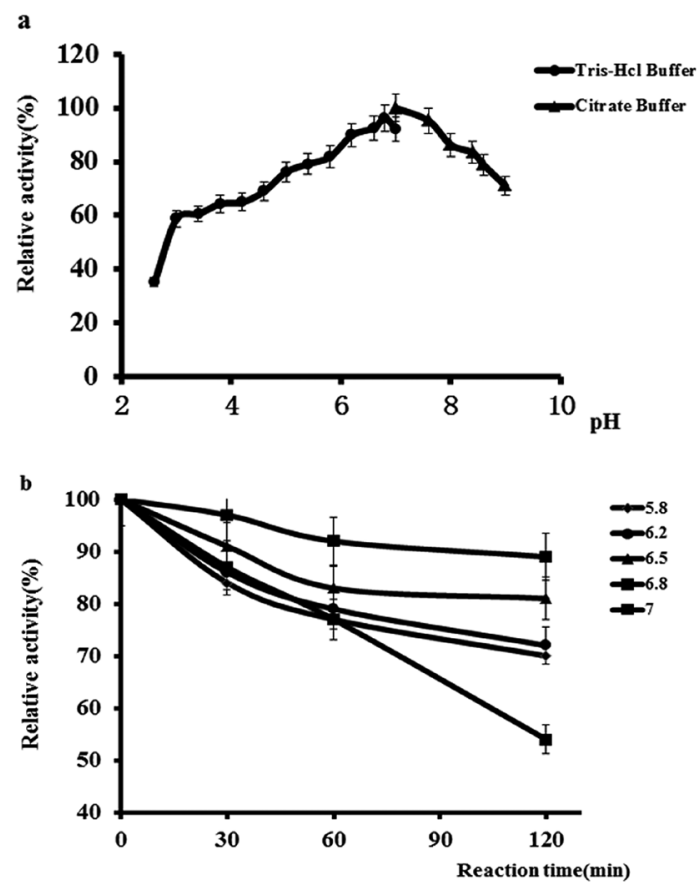

Figure 3. Optimum $\mathrm{pH}$ and $\mathrm{pH}$ stability of $H$. serotina laccase. (a) The effect of different $\mathrm{pH}$ values on laccase activity in oxidation of ABTS substrate. (b) Relative activity was tested after preincubation of the laccase at different $\mathrm{pH}$ values. The incubation time was $2 \mathrm{~h}$ for each $\mathrm{pH}$.

Table 2. Effects of metal ions on laccase activity. Relative laccase activities (\%) of the purified enzyme (dissolved in $0.1 \mathrm{M} \mathrm{Tris- \textrm {HCl }}$ buffer, pH 6.8) were determined in the presence of designed metal concentrations using ABTS as a substrate.

\begin{tabular}{lllllll}
\hline Metal & \multicolumn{1}{l}{ Relative activity } & (\% of control) & & & \\
\hline ion & $1.25 \mathrm{mM}$ & $2.5 \mathrm{mM}$ & $5 \mathrm{mM}$ & $10 \mathrm{mM}$ & $25 \mathrm{mM}$ & $50 \mathrm{mM}$ \\
\hline $\mathrm{K}+$ & $95.13 \pm 2.3$ & $94.77 \pm 1.9$ & $93.26 \pm 1.4$ & $92.54 \pm 0.7$ & $91.61 \pm 0.2$ & $89.49 \pm 1.1$ \\
\hline $\mathrm{Zn}^{2+}$ & $167.8 \pm 1.3$ & $140.5 \pm 2.1$ & $114.33 \pm 1.5$ & $106.92 \pm 1.0$ & $100.7 \pm 0.9$ & $94.55 \pm 0.6$ \\
\hdashline $\mathrm{Mn}^{2+}$ & $96.47 \pm 1.8$ & $92.64 \pm 1.7$ & $86.51 \pm 2.2$ & $62.28 \pm 2.3$ & $51.18 \pm 1.4$ & $51.08 \pm 0.5$ \\
\hline $\mathrm{Ca}^{2+}$ & $93.22 \pm 1.6$ & $87.49 \pm 1.2$ & $78.65 \pm 0.9$ & $65.38 \pm 2.4$ & $62.46 \pm 2.7$ & $43.46 \pm 0.9$ \\
\hdashline $\mathrm{Mg}^{2+}$ & $83.59 \pm 2.1$ & $71.82 \pm 1.9$ & $67.92 \pm 1.2$ & $61.81 \pm 0.3$ & $26.91 \pm 2.2$ & $28.41 \pm 1.3$ \\
\hdashline $\mathrm{Fe}^{2+}$ & $65.73 \pm 1.4$ & $58.19 \pm 1.5$ & $42.42 \pm 1.6$ & $27.55 \pm 2.4$ & $18.46 \pm 2.1$ & $15.11 \pm 2.6$ \\
\hdashline $\mathrm{Al}^{3+}$ & $94.61 \pm 1.8$ & $91.23 \pm 1.3$ & $90.22 \pm 1.2$ & $57.01 \pm 1$ & $51.55 \pm 0.8$ & $38.85 \pm 0.3$ \\
\hline
\end{tabular}

Table 3. Effects of inhibitors on laccase activity. Inhibition (\%) was measured using ABTS as a substrate after adding each inhibitor to the assay mixture (purified laccase in $0.1 \mathrm{M}$ Tris-HCl buffer, $\mathrm{pH} 6.8$ ) to attain the final concentration of inhibitor.

\begin{tabular}{lccccc}
\hline Concentration & \multicolumn{5}{c}{ Inhibition (\%) } \\
\hline$(\mathrm{mM})$ & DMSO & B-ME & EDTA & L-Cysteine & SDS \\
\hline control & 0 & 0 & 0 & 0 & 0 \\
\hline 0.75 & $4.08 \pm 2.3$ & $13.99 \pm 1.9$ & 0 & 0 & $27.97 \pm 1.2$ \\
\hdashline 1.5 & 0 & $14.76 \pm 1.6$ & 0 & 0 & $47.81 \pm 1.4$ \\
\hline 3 & 0 & $52.48 \pm 1.3$ & 0 & 0 & $84.84 \pm 2.4$ \\
\hline 6 & 0 & $78.43 \pm 2.1$ & 0 & 0 & $87.46 \pm 2.5$ \\
\hline 12.5 & 0 & 100 & 0 & $1.17 \pm 1.1$ & $87.76 \pm 2.3$ \\
\hdashline 25 & 0 & 100 & 0 & $11.08 \pm 1.5$ & $95.04 \pm 3.3$ \\
\hdashline 50 & 0 & 100 & 0 & $15.16 \pm 1.9$ & $99.42 \pm 2.1$ \\
\hline
\end{tabular}

DMSO can interact with protein hydrophobic groups and break the hydrogen bonds; $\beta$-mercaptoethanol ( $\beta$-ME) reduces disulfide bonds; EDTA is a metal ion chelating agent and can inhibit the metalloprotease activity; L-Cysteine can change the disulfide bond between protein molecules; sodium dodecyl sulfate (SDS) is an anionic detergent that can break intramolecular and intermolecular hydrogen bonds. 
Table 4. Substrate specificity of the purified $H$. serotina laccase

\begin{tabular}{lcc}
\hline Substrate & Wavelength $(\mathrm{nm})$ & Relative activity (100) \\
\hline ABTS & 420 & 100 \\
\hline N,N-Dimethyl-1,4-phenylenediamine & 515 & 42.6 \\
\hline 2-Methylcatechol & 436 & 17.2 \\
\hline Pyrogallol & 450 & 7.7 \\
\hline Tyrosine (negative control) & 280 & 0 \\
\hline
\end{tabular}

The laccase activity towards ABTS was regarded as $100 \%$.
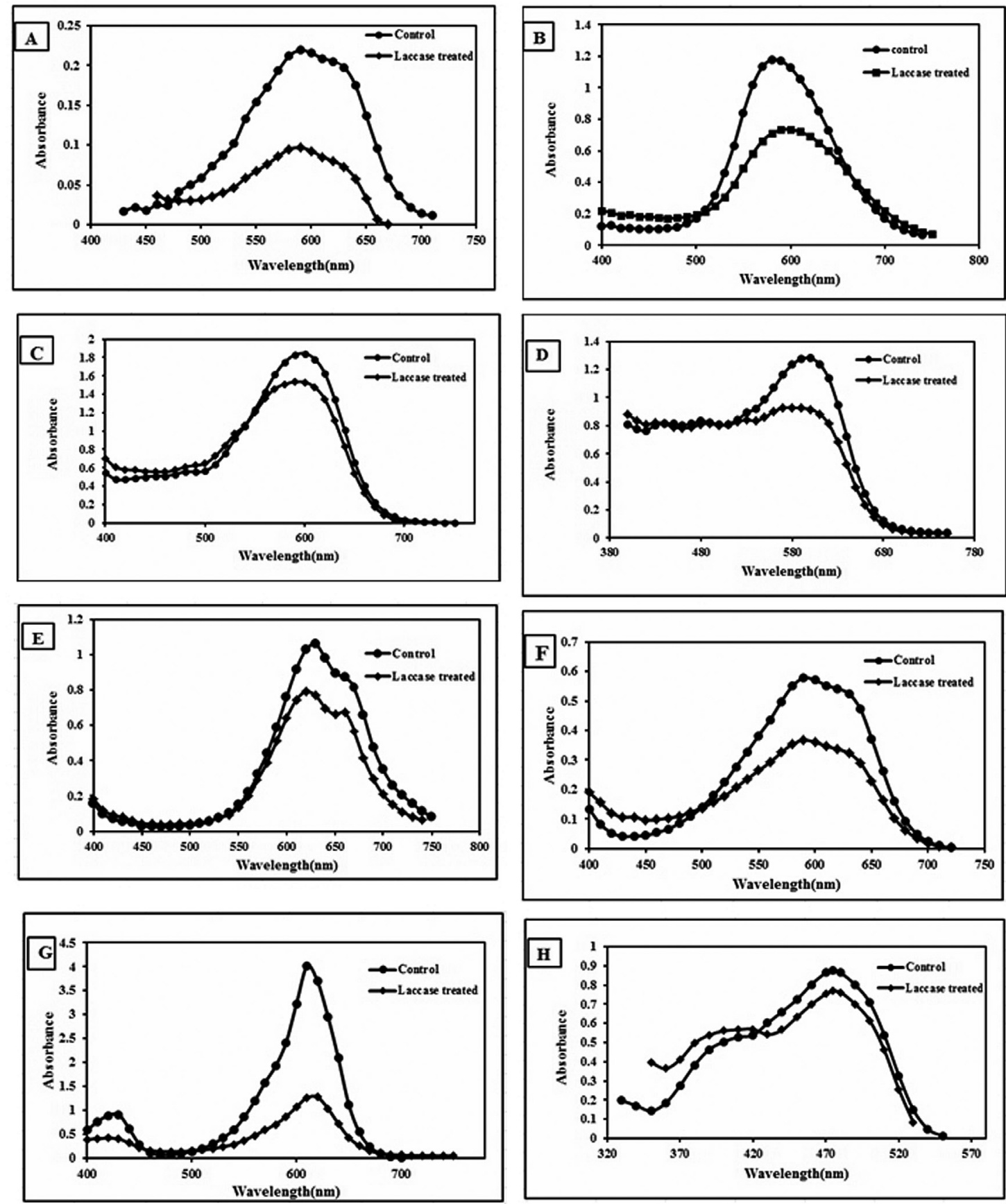

Figure 4. Full wavelength scanning of dyes before and after laccase treatment.

$A: R B B R$; $B$ : CBB; C: RW; D: K-BR; E: RES; F: R-RV; G: M-GR; H: A-OR. 


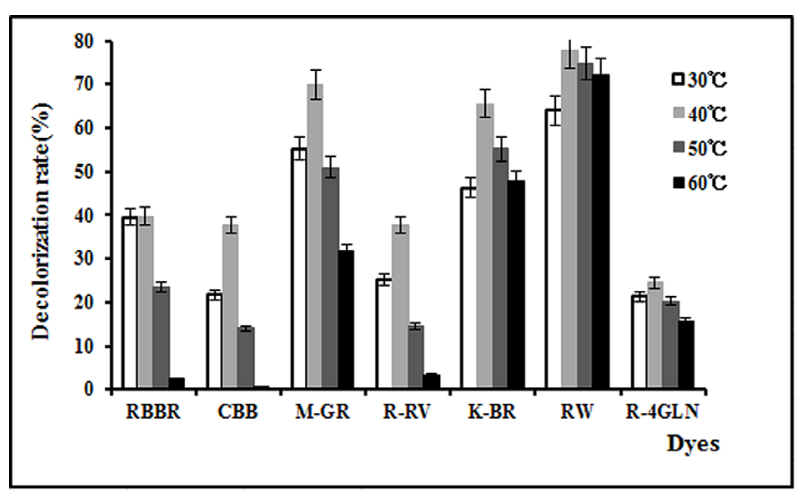

Figure 5. Optimum temperature of dye decolorization by purified laccase $\left(0.25 \mathrm{U} \mathrm{ml} \mathrm{ml}^{-1}\right)$.

The data points represent the means of triplicate assay.
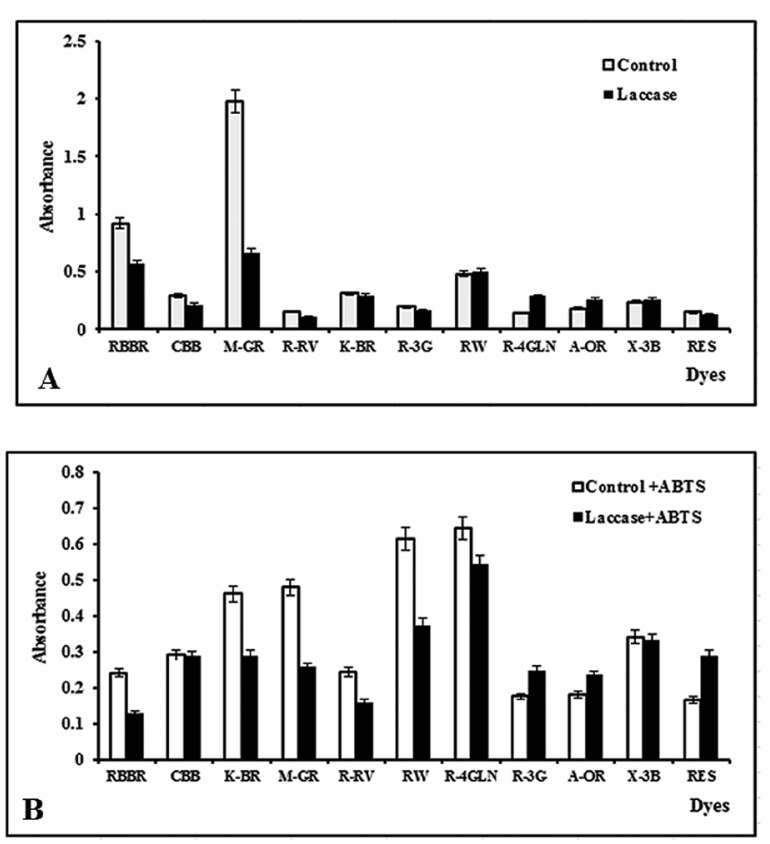

Figure 6. Media influence of dye decolorization by purified laccase $(0.25 \mathrm{U} \mathrm{ml}-1)$.

The data points represent the means of triplicate assay.

taken as the reference substrate. Approximately 42\% relative activity toward N,N-dimethyl-1,4-phenylenediamine was observed whereas approximately $17 \%$ as much activity toward 2-methylcatechol was observed, and very little activity $(\sim 8 \%)$ pyrogallol was observed. No activity toward tyrosine was observed (Table 4).

\section{Applications of purified laccase in decolorization}

The purified laccase decolorized 11 structurally different dyes. Out of the 11 tested dyes, eight dyes, namely, R-RV, RBBR, K-BR, CBB, RW, RES, A-OR and M-GR showed decolorization efficient to some degree (Fig. 4) and the effect of R-RV, RBBR, K-BR, CBB and M-GR was obvious after treatment $2 \mathrm{~h}, 4 \mathrm{~h}$ and $6 \mathrm{~h}$ (Fig. 6A).

We select M-GR with best decolorizing efficiency to detect the decoloring results with HPLC. The maximum absorption wavelengths of the degradation products were different from the relevant substrate dye and the dyes were degraded into different materials.

\section{DISCUSSION}

In the present study, we isolated a novel laccase from the edible mushroom $H$. serotina. We used ion exchange chromatography on DEAE-cellulose and CM-cellulose, and gel filtration on Superdex 75 to remove inactive proteins from the laccase-enriched chromatographic fraction. H. serotina laccase resembles that of Pleurotus sajor-caju MTCC 141 (Sahay et al., 2008) in that both are adsorbed on diethylaminoethyl (DEAE) cellulose, carboxymethyl (CM) cellulose, and Q-Sepharose and can be further purified by fast protein liquid chromatographygel filtration on a Superdex 75 column. The purification protocol resulted in 60 -fold purification of the laccase and $6.7 \%$ yield. In comparison, the laccase from the edible mushroom Pleurotus sajor-caju MTCC 141 was purified with a purification factor of 11 -fold and a $3.4 \%$ yield (Sahay et al., 2008). On the other hand, H. serotina laccase resembled laccases from other genera including Pleurotus florida (Palanivel \& Thayumanavan, 2013) and Pleurotus eous (Rani et al., 2008) laccase in optimum temperature and molecular mass, and Pleurotus nebrodensis (Tian et al., 2012) laccase in optimum $\mathrm{pH}$.

$H$. serotina laccase was a monomeric $57-\mathrm{kD}$ a protein as evidenced by the results of SDS-PAGE and gel filtration on Superdex 75. The molecular mass of the laccase was within the range of molecular masses reported in laccases from other white-rot fungi (Forootanfar et al., 2011). The laccase from $H$. serotina showed distinct characteristics such as intrinsically modest thermostability, and stability over a wide $\mathrm{pH}$ range, which render it extremely suitable for a wide scope of potential applications.

H. serotina laccase, like other fungal laccases (Call \& Mucke, 1997), non-specifically oxidized a wide range of substrates, but not tyrosine. The nature and substitution of the phenolic ring affected the oxidation activity of the laccase. The degradation activity toward substrates was ABTS $>$ N,N-dimethyl-1,4-phenylenediamine $>2$-methylcatechol>pyrogallol. In general, increasing the number of substituted methoxy groups increased the oxidation activity.

The enzymatic activity of the $H$. serotina laccase was found to be completely inhibited by SDS and $\beta-\mathrm{ME}$, which can reduce hydrogen and disulphide bonds completely. L-cysteine, which is a strong reducing agent of disulphide bonds, partially inhibited the laccase. These results indicated the existence of a disulphide structure in the active domain, and that the hydrogen bond between laccase and water or in the interior of the laccase is essential for the stability of its active domain (Luzar \& Chandler, 1993). Furthermore, EDTA had almost no effect on the laccase, thereby suggesting the absence of a metal-binding domain in the active domain. DMSO, which can interact with hydrophobic groups of proteins, also did not alter the activity of the enzyme in any way. The active domain consisted of disulphide bonds, which were important to control spatial conformation, while the hydrogen bond present in the laccase or between laccase and water was of no great importance ( $\mathrm{Hu}$ et al., 2009). A metal-binding domain was not observed in this laccase.

The laccase from $H$. serotina displayed the typical properties of an oxidoreductase as it had the capability to degrade structurally different dyes. 
Most of the dyes used in our study had a complex structure and were aromatic compounds with conjugate structures (Casieri et al., 2010). The quantity of these dyes has been increasing gradually in the environment as these dyes are now used on a large scale. They are not easily oxidized and can cause pigment sedimentation in the digestive system and lead to liver cancer (Brown \& Devito, 1993).

We chose the dyes with good decoloring effeciency to determine their optimal decoloring temperature,and the influence of ABTS on decoloring efficiency was analyzed. The efficiency of RW and R - 4GLN was improved obviously after addition ABTS, suggesting that the synthetic fixator ABTS mediated the degradation of RW and R - 4GLN. And results of HPLC have proved the validity of the conclusion.

This experiment analyzed chemical bonds maintained enzyme conformation from the angle of enzymology, and determined the characteristics of degradation about anthraquinone substrates by disposing different industrial dyes.

However, the laccase purified from $H$. serotina can specifically degrade anthraquinone dyes, and is highly advantageous in bioremediation and biotransformation of regions polluted by industrial waste containing toxic and recalcitrant dyes. These studies in conjunction with other mediators of interest can provide effective environmental engineering strategies for remediation.

\section{Acknowledgments}

This work was supported by a grant from the Major State Research Development Program of China (the National 973 Program) (NO. 2010CB732202) and a grant from the Modern Agricultural Industry Technology System Beijing Innovation Team (Edible Mushroom).

\section{REFERENCE}

Asgher M, Bhatti HN, Ashraf M, Legge RL (2008) Recent developments in biodegradation of industrial pollutants by white rot fungi and their enzyme system. Biodegradation 19: 771-783. DOI: 10.1007/ s10532-008-9185-3

Baldrian P (2006) Fungal laccases - occurrence and properties. Fems Microbiol Rev 30: 215-242. DOI: 10.1111/j.1574-4976.2005.00010.x.

Brown MA, Devito SC (1993) Predicting azo-dye toxicity. Crit Rev Env Sci Tech 23: 249-324.

Call HP, Mucke I (1997) History, overview and applications of mediated lignolytic systems, especially laccase-mediator-systems (Lignozym (R)-process). J Biotechnol 53: 163-202. DOI: 10.1016/S01681656 (97)01683-0.

Casieri L, Anastasi A, Prigione V, Varese GC (2010) Survey of ectomycorrhizal, litter-degrading, and wood-degrading Basidiomycetes for dye decolorization and ligninolytic enzyme activity Anton Leeuw. Int J G 98: 483-504. DOI: 10.1007/s10482-010-9466-9.

Cea M, Jorquera M, Rubilar O, Langer H, Tortella G, Diez MC (2010) Bioremediation of soil contaminated with pentachlorophenol by Anthracophyllum discolor and its effect on soil microbial community. J Hazard Mater 181: 315-323. DOI: 10.1016/j.jhazmat.2010.05.013.

Champagne PP, Ramsay J (2007) Reactive blue 19 decolouration by laccase immobilized on silica beads. Appl Microbiol Biot 77: 819-823. DOI: $10.1007 /$ s00253-007-1208-1.

Enayatzamir K, Alikhani HA, Couto SR (2009) Simultaneous production of laccase and decolouration of the diazo dye Reactive Black 5 in a fixed-bed bioreactor. I Hazard Mater 164: 296-300. DOI: 10.1016/j.jhazmat.2008.08.032.

Forootanfar H, Faramarzi MA, Shahverdi AR, Yazdi MT (2011) Purification and biochemical characterization of extracellular laccase from the ascomycete Paraconiothyrium variabile. Bioresource Technol 102: 1808-1814.

Freixo MD, Karmali A, Arteiro JM (2012) Production, purification and characterization of laccase from Pleurotus ostreatus grown on tomato pomace. World J Microb Biot 28: 245-254. DOI: 10.1007/ s11274-011-0813-4.
Giardina P, Faraco V, Pezzella C, Piscitelli A, Vanhulle S, Sannia G (2010) Laccases: a never-ending story. Cell Mol Life Sci 67: 369-385. DOI: $10.1007 /$ s00018-009-0169-1.

Gutierrez A, Rencoret J, Cadena EM, Rico A, Barth D, del Rio JC, Martinez AT (2012) Demonstration of laccase-based removal of lignin from wood and non-wood plant feedstocks. Bioresource Technol 119: 114-122. DOI: 10.1016/j.biortech.2012.05.112.

Halaburgi VM, Sharma S, Sinha M, Singh TP, Karegoudar TB (2011) Purification and characterization of a thermostable laccase from the ascomycetes Cladosporium cladosporioides and its applications. Process Biochemistry 46: 1146-1152. DOI: 10.1016/j.procbio.2011.02.002.

Hilden K, Hakala TK, Lundell T (2009) Thermotolerant and thermostable laccases. Biotechnol Lett 31: 1117-1128. DOI: 10.1007/s10529009-9998-0.

Hu MR, Chao YP, Zhang GQ, Xue ZQ, Qian S (2009) Laccase-mediator system in the decolorization of different types of recalcitrant dyes. I Ind Microbiol Biotechnol 36: 45-51.

Jia JB, Zhang SP, Wang P, Wang HJ (2012) Degradation of high concentration 2,4-dichlorophenol by simultaneous photocatalytic-enzymatic process using TiO2/UV and laccase. J Hazard Mater 205: 150-155. DOI: 10.1016/j.jhazmat.2011.12.052.

Kahraman S, Yesilada O (2001) Industrial and agricultural wastes as substrates for laccase production by white-rot fungi Folia Microbiol 46:133-136 doi:Doi 10.1007/Bf02873591.

Khandare RV, Rane NR, Waghmode TR, Govindwar SP (2012) Bacterial assisted phytoremediation for enhanced degradation of highly sulfonated diazo reactive dye. Environ Sci Pollut R 19: 1709-1718. DOI: $10.1007 /$ s11356-011-0679-x.

Khlifi R, Belbahri L, Woodward S, Ellouz M, Dhouib A, Sayadi S, Mechichi T (2010) Decolourization and detoxification of textile industry wastewater by the laccase-mediator system. I Hazard Mater 175: 802-808. DOI: 10.1016/j.jhazmat.2009.10.079.

Kim SJ, Shoda M (1999) Purification and characterization of a novel peroxidase from Geotrichum candidum Dec 1 involved in decolorization of dyes. Appl Environ Microb 65: 1029-1035.

Luzar A, Chandler D (1993) Structure and hydrogen-bond dynamics of water-dimethyl sulfoxide mixtures by computer-simulations. $J$ Chem Phys 98: 8160-8173. DOI: 10.1063/1.464521.

Meng XM, Liu GF, Zhou JT, Fu QS, Wang GH (2012) Azo dye decolorization by Shewanella aquimarina under saline conditions. Bioresource Technol 114: 95-101. DOI: 10.1016/j.biortech.2012.03.003.

Mohorcic M, Teodorovic S, Golob V, Friedrich J (2006) Fungal and enzymatic decolourisation of artificial textile dye baths. Chemosphere 63: 1709-1717. DOI: 10.1016/j.chemosphere.2005.09.063.

Palanivel S, Thayumanavan P (2013) Purification and characterization of Pleurotus florida laccase (L1) involved in the Remazol Brilliant Blue R (RBBR) decoloration. J Environ Treatment Techniq 1: 24-34.

Rani P, Kalyani N, Prathiba K (2008) Evaluation of lignocellulosic wastes for production of edible mushrooms. Appl Biochem Biotech 151: $151-159$.

Robinson T, Nigam PS (2008) Remediation of textile dye waste water using a white-rot fungus Bjerkandera adusta through solid-state fermentation (SSF). Appl Biochem Biotech 151: 618-628. DOI: 10.1007/ s12010-008-8272-6.

Sahay R, Yadav RSS, Yadav KDS (2008) Purification and characterization of extracellular laccase secreted by Pleurotus sajor-caju MTCC 141. Chin J Biotech 24: 2068-2072 (Sheng Wu Gong Cheng Xue Bao).

Saranyu KR (2009) accase activity from fresh fruiting bodies of MK05:purification and remazol brilliant blue $\mathrm{R}$ decolorization. $J$ Biol Sci 1: 5 .

Shraddha, Shekher R, Sehgal S, Kamthania M, Kumar A (2011) Laccase: microbial sources, production, purification, and potential biotechnological applications. Enzyme Res 2011: 217861.

Tian G-T, Zhang G-Q, Wang H-X, Ng TB (2012) Purification and characterization of a novel laccase from the mushroom Pleurotus nebrodensis. Acta Biochim Pol 59: 407-412.

Verma AK, Raghukumar C, Verma P, Shouche YS, Naik CG (2010) Four marine-derived fungi for bioremediation of raw textile mill effluents. Biodegradation 21: 217-233. DOI: 10.1007/s10532-009-9295-

Villalba LL, Fonseca MI, Giorgio M, Zapata PD (2010) White rot fungi laccases for biotechnological applications. Recent Pat DNA Gene Seq 4: 106-112.

Wu YR, Luo ZH, Chow RKK, Vrijmoed LLP (2010) Purification and characterization of an extracellular laccase from the anthracene-degrading fungus Fusarium solani MAS2. Bioresource Technol 101: 97729777. DOI: 10.1016/j.biortech.2010.07.091.

Zhao D, Zhang X, Cui DZ, Zhao M (2012) Characterisation of a novel white laccase from the deuteromycete fungus Myrothecium verrucaria NF-05 and its decolourisation of dyes. Plos One 7: ARTN e38817. DOI: 10.1371 /journal.pone.0038817. 